\title{
Effect of Echium oil compared with marine oils on lipid profile and inhibition of hepatic steatosis in LDLr knockout mice
}

Patrícia Borges Botelho ${ }^{1}$, Karina da Rocha Mariano ${ }^{1}$, Marcelo Macedo Rogero ${ }^{2}$ and Inar Alves de Castro ${ }^{{ }^{*}}$

\begin{abstract}
Background: In an effort to identify new alternatives for long-chain n-3 polyunsaturated fatty acids (LC n-3 PUFA) supplementation, the effect of three sources of omega 3 fatty acids (algae, fish and Echium oils) on lipid profile and inflammation biomarkers was evaluated in LDL receptor knockout mice.

Methods: The animals received a high fat diet and were supplemented by gavage with an emulsion containing water (CON), docosahexaenoic acid (DHA, 42.89\%) from algae oil (ALG), eicosapentaenoic acid (EPA, 19.97\%) plus DHA (11.51\%) from fish oil (FIS), and alpha-linolenic acid (ALA, 26.75\%) plus stearidonic acid (SDA, 11.13\%) from Echium oil (ECH) for 4 weeks.

Results: Animals supplemented with Echium oil presented lower cholesterol total and triacylglycerol concentrations than control group (CON) and lower VLDL than all of the other groups, constituting the best lipoprotein profile observed in our study. Moreover, the Echium oil attenuated the hepatic steatosis caused by the high fat diet. However, in contrast to the marine oils, Echium oil did not affect the levels of transcription factors involved in lipid metabolism, such as Peroxisome Proliferator Activated Receptor a (PPAR a) and Liver X Receptor a (LXR a), suggesting that it exerts its beneficial effects by a mechanism other than those observed to EPA and DHA. Echium oil also reduced N-6/N-3 FA ratio in hepatic tissue, which can have been responsible for the attenuation of steatosis hepatic observed in ECH group. None of the supplemented oils reduced the inflammation biomarkers.
\end{abstract}

Conclusion: Our results suggest that Echium oil represents an alternative as natural ingredient to be applied in functional foods to reduce cardiovascular disease risk factors.

Keywords: Atherosclerosis, Inflammation, Echium, Stearidonic, Omega 3, Steatosis

\section{Background}

The increased intake of omega- 6 fatty acids during the 20th century as a result of an elevation in vegetal oil consumption (of more than 1,000-fold) contributed to a decline in the tissue concentration of long-chain $\mathrm{n}-3$ polyunsaturated fatty acids (LC n-3 PUFA) [1,2], which might be associated with the increased incidence of inflammatory disorders, such as atherosclerosis [3]. The development of atherosclerotic plaques is associated with several clinical cardiovascular events. Considering the health effects of LC n-3 PUFA toward the reduction

\footnotetext{
* Correspondence: inar@usp.br

'LADAF. NAPAN. Department of Food and Experimental Nutrition, Faculty of Pharmaceutical Sciences, University of São Paulo, Av. Lineu Prestes, 580, São Paulo B14 - 05508-900, Brazil

Full list of author information is available at the end of the article
}

of cardiovascular disease (CVD) risk [4,5], many industries have added eicosapentaenoic acid (EPA) and docosahexaenoic acid (DHA) from marine oils to food formulations or supplements, aiming to explore this health claim. In 2004, the Food and Drug Administration (FDA) qualified the health claim of products containing EPA and DHA [6]. A similar recommendation was also provided by the American Heart Association (AHA), who suggested consumption of $1 \mathrm{~g} /$ day of $\mathrm{EPA}+\mathrm{DHA}$ for patients with CVD and 2-4 g/day for patients with hypertriglyceridaemia [7].

The cardioprotective effects of LC N-3 PUFA appear to be due to a synergism between multiple mechanisms including triacylglycerol (TG) lowering, improving membrane fluidity, anti-inflammatory, antiarrhythmic and

\section{Biomed Central}


antithrombotic effects [5]. The scientific evidence concerning the beneficial effects of the LC N-3 PUFA on lipid profile and inflammation were obtained from several studies using animal and human models. However, these effects and the mechanisms by which they occur are restricted to the action of EPA and DHA [8]. Other non-marine sources of omega 3 fatty acids (N-3 FA), such as alpha- linolenic acid (ALA) or stearidonic acid (SDA), can be converted in vivo to EPA and DHA by the desaturase and elongase enzymes in a tissue-dependent manner, the liver being the major site of this conversion [9]. It has been reported that the conversion rate of ALA is low (5-10\% for EPA and < 1\% for DHA), which diminishes the efficacy of these alternative sources in the reduction of cardiovascular risk [10-12]. However, due to dietary preferences, safety, sustainability, cost and oxidative stability aspects, other non-marine oils alternatives must be evaluated $[3,9-11,13,14]$. It has been suggested that the low rate by which ALA is converted to EPA is a result of the limited activity of $\Delta 6$-desaturase when linoleic acid (LNA) is also present [15]. However SDA, a precursor of EPA that is found in plants, such as Echium (Echium plantagineum), black currant seed and other genetically modified seeds, does not need $\Delta 6$-desaturase activity to be converted into EPA $[3,10]$. In an effort to identify new alternatives for LC N-3 PUFA supplementation, the objective of this study was to compare the effects of three sources of N-3 FA (algae, fish and Echium oil) on lipid composition and some inflammatory biomarkers using LDL receptor deficient mice (LDLr knockout mice) as model.

\section{Methods}

\section{Oils and reagents}

The N-3 FA used in this study were commercial products: the algae oil containing 40\% DHA (DHASCO) was obtained from Martek Biosciences ${ }^{\circledR}$ (Winchester, KY, USA), the fish oil (EPA1T1600 MEG- ${ }^{\mathrm{rm}}$ ) containing EPA $(20 \%)+$ DHA (12\%) was obtained from Ocean Nutrition ${ }^{\circledR}$ (Dartmouth, NS, Canada) and the Echium oil containing 11.5\% SDA (AW39144ECH) was obtained from Oil Seed Extraction $^{\circledR}$ (Ashburton, New Zealand). All reagents were purchased from Sigma Chemical Co. (St. Louis, MO, USA), Merck (Darmstadt, Germany), Calbiochem Technology Inc. (Boston, MA, USA) and GE Healthcare (Little Chalfont, Bucks, UK). The aqueous solutions were prepared with ultra-pure Milli-Q water (Millipore Ind. Com. Ltd., SP, Brazil), and the organic solvents were of HPLC grade. Fatty acids profile of the oils used in this study was analyzed by gas chromatography and is shown in Table 1.

\section{Animals and diets}

Forty male homozygous LDL receptor-deficient mice (LDLr Knockout mice, C57BL/6) weighing 25-29 g
Table 1 Fatty acids composition of the edible oils applied in this study

\begin{tabular}{llll}
\hline Fatty acids (g/100 g total FA) & Fish oil & Algae oil & Echium oil \\
\hline C10:0 - capric & - & 1.12 & - \\
C12:0 - lauric & - & 4.92 & - \\
C14:0 - miristic & 7.93 & 10.19 & - \\
C16:0 - palmitic & 17.05 & 6.97 & 5.15 \\
C18:0 - stearic & 3.05 & 0.92 & 2.57 \\
C16:1 - palmitoleic & 9.76 & 2.82 & - \\
C18:1 - oleic (n-9) & 13.20 & 27.48 & 12.77 \\
C18:2 - (LNA) linoleic (n-6) & 1.19 & 1.17 & 27.52 \\
C18:3 - (ALA) a-linolenic (n-3) & 0.68 & - & 26.75 \\
C18:3 - (GLA) Y- linolenic (n-6) & - & - & 13.11 \\
C18:4 - (SDA) stearidonic (n-3) & 3.28 & - & 11.13 \\
C20:4- (ARA) arachidonic (n-6) & 1.82 & - & - \\
C20:5 - (EPA) eicosapenatenoic (n-3) & 19.97 & - & - \\
C22:5 - (DPA) docosapentaenoic (n-3) & 2.20 & 0.38 & - \\
C22:6 - (DHA) docosaexaenoic (n-3) & 11.51 & 42.89 & - \\
E saturated FA & 28.03 & 24.12 & 7.72 \\
E monounsaturated FA & 22.96 & 30.30 & 12.77 \\
E polyunsaturated FA & 40.65 & 44.44 & 78.51 \\
N-6 FA & 3.01 & 1.17 & 40.63 \\
N-3 FA & 37.64 & 43.27 & 37.88 \\
N-6/N-3 FA ratio & 0.08 & 0.03 & 1.07 \\
\hline
\end{tabular}

(4.0-4.5 months of age) were purchased from the Faculty of Pharmaceutical Sciences (São Paulo, Brazil). The mice were housed in plastic cages (5 animals/cage) at constant temperature $\left(22 \pm 2^{\circ} \mathrm{C}\right)$ and relative humidity (55 $\pm 10 \%)$, with a 12-h light-dark cycle. Food and water were available ad libitum, and animals were divided into four groups. All groups were fed with a high fat diet for 4 weeks (Table 2), and were supplemented with an oil-in-water emulsion $(190-240 \mu \mathrm{L} / \mathrm{d})$ per mouse containing fish oil (FIS), algae oil (ALG), Echium oil $(\mathrm{ECH})$ or water $(\mathrm{CON})$ by gavage. Amount of EPA, DHA, SDA and ALA ingested from added oil per day is presented in Table 3 . We opted to compare the effect of the same amount of EPA+DHA in all groups. To achieve this objective the rate of conversion from SDA to EPA (4:1) proposed by Whelan [16] was adopted in our study. By this way, the EPA+DHA dosage applied was $0.7,0.8$ and $0.7 \mathrm{mg} /$ day using Fish, Alagae and Echium oil respectively (Table 3 ). The emulsions were prepared weekly by mixing the respective oil with water using a high-pressure homogenizer (Homolab mod A-10, Alitec, São Paulo, Brazil). The emulsions were prepared in less than 2 minutes, and the temperature was kept below $40^{\circ} \mathrm{C}$, during this short time. After, the emulsions were transferred to $2 \mathrm{~mL}$ eppendorf tubes, immediately 
Table 2 Composition and major fatty acids profile of the high fat diet

\begin{tabular}{|c|c|}
\hline Composition $^{2}$ & High fat diet $^{1}$ \\
\hline Moisture (g/100 g) & $7.22 \pm 0.05$ \\
\hline Ashes (g/100 g) & $2.94 \pm 0.10$ \\
\hline Protein $(\mathrm{g} / 100 \mathrm{~g})$ & $17.99 \pm 0.49$ \\
\hline Lipids (g/100 g) & $30.72 \pm 0.57$ \\
\hline Carbohydrate (g/100 g) & $41.13 \pm 0.33$ \\
\hline Energy (Kcal/100 g) & $512.96 \pm 3.32$ \\
\hline \multicolumn{2}{|l|}{ Fatty acids (g/100 g total FA) } \\
\hline C10:0 - capric & $0.81 \pm 0.00$ \\
\hline C12:0 - lauric & $1.03 \pm 0.17$ \\
\hline C14:0 - miristic & $1.68 \pm 0.01$ \\
\hline C16:0 - palmitic & $26.20 \pm 0.62$ \\
\hline C18:0 - stearic & $17.30 \pm 0.05$ \\
\hline C16:1 - palmitoleic & $0.96 \pm 0.07$ \\
\hline C18:1 n-9 - oleic & $32.73 \pm 0.12$ \\
\hline C18:2 - (LNA) linoleic (n-6) & $11.94 \pm 0.97$ \\
\hline C18:3 - (ALA) a-linolenic (n-3) & $0.60 \pm 0.06$ \\
\hline C18:3 - (GLA) Y- linolenic (n-6) & $0.25 \pm 0.06$ \\
\hline C18:4 - (SDA) stearidonic (n-3) & - \\
\hline C20:0 - arachidic & $0.27 \pm 0.01$ \\
\hline C20:1 - eicosaenoic (n-9) & $0.59 \pm 0.05$ \\
\hline C20:2- eicosadienoic (n-6) & $0.26 \pm 0.02$ \\
\hline C20:4- (ARA) arachidonic (n-6) & - \\
\hline C20:5 - (EPA) eicosapenatenoic $(n-3)$ & - \\
\hline C22:5 - (DPA) docosapentaenoic ( $n-3)$ & - \\
\hline C22:6 - (DHA) docosaexaenoic $(n-3)$ & - \\
\hline $\mathrm{NI}$ & 5.15 \\
\hline
\end{tabular}

1 Based on Safwat et al. [30].

${ }^{2}$ Diet was composed by $187.0 \mathrm{~g}$ casein, $133.5 \mathrm{~g}$ sucrose, $300.0 \mathrm{~g}$ lard, $193.5 \mathrm{~g}$ corn starch, $67.0 \mathrm{~g}$ cellulose, $53.5 \mathrm{~g}$ soybean oil, $46.5 \mathrm{~g}$ minerals, $2.4 \mathrm{~g} \mathrm{~L}$ cystine, $3.3 \mathrm{~g}$ choline bitartrate and $13.35 \mathrm{~g}$ vitamin mix/ kg diet. $\mathrm{NI}$, not identified.

immersed in nitrogen and kept at $-80^{\circ} \mathrm{C}$ until the time of gavage. All this procedure was repeated twice a week. Emulsion characteristics are presented in Table 3. Diet consumption was measured daily and animals were weighed individually twice a week. After 4 weeks, the mice were fasted for $12 \mathrm{~h}$, and anaesthetised with a mixture containing xylazine 2\% (Sespo Ind. e Com. Ltda., Paulínia, Brazil), ketamine (Syntec do Brasil Ltda., Cotia, Brazil) and acepromazine (Vetnil Ind. e Com. de Prod. Veterinários Ltda., Louveira, Brazil). Blood samples collected from the brachial plexus were immediately centrifuged $(1,600 \times \mathrm{g}$ for $15 \mathrm{~min}$ at $4^{\circ} \mathrm{C}$ ), frozen under liquid nitrogen and stored $\left(-80^{\circ} \mathrm{C}\right)$ for further analysis. The liver was excised, dried with lint and weighed. Small pieces of the larger lobe were frozen for Western blotting and further analysis, and a piece of the smaller lobe was immersed in $10 \%$ buffered
Table 3 Characteristics of the emulsions prepared with three N-3 FA sources

\begin{tabular}{lccc}
\hline & \multicolumn{3}{c}{ Emulsions } \\
\cline { 2 - 5 } Characteristics $^{1}$ & Fish & Algae & Echium \\
\hline Emulsion volume $(\mu \mathrm{L} / \mathrm{d})$ & 240 & 190 & 270 \\
Oil in the emulsion $(\%)$ & 1 & 1 & 10 \\
Oil supplementation $(\mu \mathrm{L} / \mathrm{d})$ & 2.4 & 1.9 & 27.0 \\
Oil supplementation $(\mathrm{mg} / \mathrm{d})$ & 2.2 & 1.8 & 25.1 \\
C20:5 - (EPA) eicosapenatenoic $(\mathrm{n}-3)(\mathrm{mg} / \mathrm{d})$ & 0.44 & - & - \\
C22:6 - $(\mathrm{DHA})$ docosaexaenoic $(\mathrm{n}-3)(\mathrm{mg} / \mathrm{d})$ & 0.25 & 0.77 & - \\
C18:4 - $(\mathrm{SDA})$ stearidonic $(\mathrm{n}-3)(\mathrm{mg} / \mathrm{d})$ & 0.07 & - & $2.79^{2}$ \\
C18:3 - (ALA) linolenic $(\mathrm{n}-3)(\mathrm{mg} / \mathrm{d})$ & 0.01 & - & 6.71 \\
C22:5 - (DPA) docosapentaenoic $(\mathrm{n}-3)(\mathrm{mg} / \mathrm{d})$ & 0.05 & 0.01 & - \\
N-6 FA from gavage $(\mathrm{mg} / \mathrm{d})$ & 0.07 & 0.02 & 10.20 \\
N-3 FA from gavage $(\mathrm{mg} / \mathrm{d})$ & 0.82 & 0.78 & $9.50^{1}$ \\
N-6 FA from diet $(\mathrm{mg} / \mathrm{d})$ & 80.07 & 80.02 & 80.00 \\
N-3 FA from diet $(\mathrm{mg} / \mathrm{d})$ & 4.00 & 4.00 & 4.00 \\
Total N-6 FA (mg/d) & 80.07 & 80.02 & 90.20 \\
Total N-3 FA (mg/d) & 4.82 & 4.78 & 13.50 \\
N-6/N-3 FA ratio & 16.6 & 16.7 & 6.7 \\
\hline
\end{tabular}

${ }^{1}$ Supplementation is expressed as $\mathrm{mg} / \mathrm{d} / \mathrm{animal}$.

${ }^{2}$ Assumed no conversion from ALA to EPA and equivalence from SDA to EPA of $25 \%$, according to Whelan [16], resulting in about $0.70 \mathrm{mg} / \mathrm{d}$.

formalin solution for histopathological examination. Subsequently, the animals were perfused with a cold $\mathrm{NaCl}$ solution $(0.9 \%, 240.0 \mathrm{~mL})$ via their left ventricle to remove the excess of blood. The animal protocol was approved by the Ethics Committee for Animal Studies of the Faculty of Pharmaceutical Sciences (São Paulo, Brazil).

\section{Measurements}

Fatty acids were isolated from the liver and diets using the extraction methodology proposed by the Association of Official Analytical Chemists (method 996.06) [17]. The fatty acid methyl esters (FAME) were suspended in hexane and analyzed by a gas chromatograph (GC17A Shimadzu Class CG, Kyoto, Japan) equipped with a $30 \mathrm{~m} \times 0.25 \mathrm{~mm}$ (i.d.), $0.25 \mu \mathrm{m}$ film thickness fused silica capillary column (Supelcowax, Bellefont, PA, USA) and a flame ionization detector. Helium was used as a carrier gas, and the fatty acids were separated using a $10^{\circ} \mathrm{C} / \mathrm{min}$ gradient from 80 to $150^{\circ} \mathrm{C}$ and then a $6^{\circ} \mathrm{C} / \mathrm{min}$ gradient from $150^{\circ} \mathrm{C}$ to $230^{\circ} \mathrm{C}$. Standard mixtures with 37 FAME and PUFA 3 methyl esters from Menhaden oil (Sigma Chemical, St. Louis, MO, USA) was used to identify the peaks. The results were expressed as percentage of the total fatty acids present.

The serum lipoprotein concentrations, including total cholesterol, high density lipoprotein (HDL) and TG, were quantified using an enzymatic colorimetric test from Labtest (Lagoa Santa, MG, Brazil). The low density 
lipoprotein levels (LDL) and VLDL were estimated using the Friedewald formula [18]. The inflammation biomarkers (C-reactive protein (CRP), interleukin-6 (IL-6) vascular cell-adhesion molecule-1 (VCAM), Inter-Cellular Adhesion Molecule (ICAM) and adiponectin) were analysed in serum samples using Multiplex commercial Kits (Millipore, St. Charles, MO, USA).

\section{Liver histology}

The representative liver fragments were fixed in a $10 \%$ buffered formalin solution for approximately 48 hours. Then, the fragments were fixed in paraffin. The material was submitted to microtomy with a cut of $5 \mu \mathrm{m}$ and stained with hematoxylin and eosin for histopathological evaluation [19].

\section{Western blotting analysis of hepatic peroxisome proliferator activated receptor a (PPARa) and liver $X$ receptor a (LXRa)}

The total nuclear protein was extracted from the frozen liver tissue samples using the specific commercial Kit NEPER (GE Healthcare, Little Chalfont, Bucks, UK). Subsequently, $15 \mu \mathrm{g}$ of the proteins present in the supernatant was separated on a 10\% SDS-PAGE gel and trans-

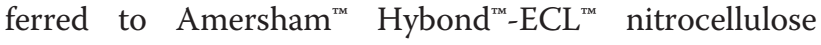
membranes (GE Healthcare UK Ltd.-Amershan Place, Little Chalfont, Buckinghamshire, UK) using a humid system composed of buffer containing $25 \mathrm{mM}$ Tris base, $192.0 \mathrm{mM}$ glycine, $0.02 \% \mathrm{SDS}$, and 10\% methanol (GE Healthcare, Little Chalfont, Bucks, UK). The membranes were then blocked with 5\% ECL advance blocking agent in TBST (Tris-buffered saline and Tween 20) for $1.5 \mathrm{~h}$ to prevent the occurrence of nonspecific binding, and they were incubated with primary antibodies (rabbit polyclonal to LXR $\alpha-$ ab 82774 and rabbit polyclonal to PPAR $\alpha$ - ab 8934, ABCAM plc., Cambridge, MA, USA) diluted in a ratio of 1:345 and 1:500, respectively. After this step, the membranes were incubated for $1 \mathrm{~h}$ at $4^{\circ} \mathrm{C}$ with a secondary antibody conjugated to horseradish peroxidase (GE Healthcare, Little Chalfont, Bucks, UK). Following three washes in TBST, the immunoreactive bands were visualised using the ECL advance detection system (Amersham Biosciences, Pittsburgh, PA, USA). To standardise the immunoblots, a digital detection system was applied (IMAGE QUANTTM 400 version 1.0.0, Amersham Biosciences, Pittsburgh, PA, USA) using proliferating cell nuclear antigen - PCNA (ABCAM plc., Cambridge, MA, USA) as standard. The densitometry was quantified using the Discovery series ${ }^{\text {tw }}$ Quantity one ${ }^{\circledR}$ Analysis Software version 4.6.3 (Bio-Rad Laboratories Inc., Hercules, CA, USA).

\section{Statistical analysis}

The effect of each N-3 FA source on biomarkers was compared by one-way ANOVA and Tukey HSD test. Equivalent non-parametric ANOVA was applied when there was no homogeneity of variances (Hartley test). A probability value of 0.05 was adopted to reject the null hypothesis. All calculations and graphs were performed using the software Statistica v.9 (Statsoft Inc., Tulsa, USA).

\section{Results}

All groups showed the same weight gain and diet consumption (Table 4). Animals supplemented with Echium oil presented lower total cholesterol and triacylglycerol concentrations than Control, and lower

Table 4 Body weight, diet consumption, plasma lipid profile and inflammatory biomarkers observed in the supplemented groups

\begin{tabular}{|c|c|c|c|c|c|}
\hline & CON & FIS & ALG & $\mathrm{ECH}$ & $P^{1}$ \\
\hline Initial weight (g) & $26.9 \pm 1.3$ & $26.8 \pm 0.6$ & $27.3 \pm 0.1$ & $27.8 \pm 0.8$ & 0.670 \\
\hline Final weight (g) & $28.9 \pm 2.0$ & $28.3 \pm 0.6$ & $29.8 \pm 1.4$ & $28.8 \pm 0.5$ & 0.731 \\
\hline Weight gain (g) & $2.0 \pm 0.7$ & $1.5 \pm 0.0$ & $2.5 \pm 1.3$ & $1.1 \pm 1.3$ & 0.542 \\
\hline Diet consumption ( $\mathrm{g} / \mathrm{d} /$ mouse) & $2.3 \pm 0.2$ & $2.3 \pm 0.1$ & $2.3 \pm 0.1$ & $2.4 \pm 0.3$ & 0.886 \\
\hline Cholesterol (mg/100 mL) & $371.7 \pm 37.4^{a}$ & $349.8 \pm 37.2^{\mathrm{ab}}$ & $350.2 \pm 56.3^{\mathrm{ab}}$ & $312.9 \pm 40.2^{b}$ & 0.040 \\
\hline LDL (mg/100 mL) & $244.3 \pm 32.2$ & $240.4 \pm 34.2$ & $227.6 \pm 50.4$ & $199.3 \pm 31.4$ & 0.054 \\
\hline $\mathrm{HDL}(\mathrm{mg} / 100 \mathrm{~mL})$ & $95.9 \pm 8.8$ & $82.7 \pm 13.7$ & $95.0 \pm 8.4$ & $92.0 \pm 13.7$ & 0.050 \\
\hline VLDL (mg/100 mL) & $29.7 \pm 4.6^{a}$ & $26.7 \pm 5.1^{a}$ & $27.6 \pm 9.7^{a}$ & $21.6 \pm 3.5^{b}$ & 0.036 \\
\hline Triacylglicerol (mg/100 mL) & $149.0 \pm 23.6^{a}$ & $133.6 \pm 25.4^{\mathrm{ab}}$ & $115.8 \pm 34.2^{b}$ & $109.1 \pm 17.5^{b}$ & 0.008 \\
\hline CRP $(\mathrm{ng} / \mathrm{mL})$ & $121.6 \pm 5.5$ & $118.9 \pm 6.7$ & $118.0 \pm 9.6$ & $124.6 \pm 8.6$ & 0.232 \\
\hline IL-6 (pg/mL) & $11.4 \pm 2.3$ & $10.6 \pm 2.0$ & $10.1 \pm 1.9$ & $11.2 \pm 2.0$ & 0.457 \\
\hline VCAM (pg/mL) & $1.7 \pm 0.4$ & $1.7 \pm 0.3$ & $1.6 \pm 0.5$ & $1.3 \pm 0.2$ & 0.059 \\
\hline ICAM (ng/mL) & $39.3 \pm 6.7$ & $36.9 \pm 3.8$ & $39.2 \pm 4.4$ & $35.4 \pm 3.4$ & 0.188 \\
\hline ADIPONECTIN (pg/mL) & $13.9 \pm 8.3$ & $14.4 \pm 6.0$ & $11.5 \pm 3.7$ & $14.3 \pm 9.3$ & 0.805 \\
\hline
\end{tabular}

\footnotetext{
${ }^{1}$ Probability value obtained by ANOVA. Values followed by the same letter are not significantly different at the $0.05 ; a, b: p<0.05(n=10 / g r o u p)$.
} 
VLDL than all of the other groups, constituting the best lipoprotein profile observed in this study. None of the N-3 FA sources altered any of the inflammation biomarkers (Table 4). The effect of N-3 FA associated with high fat diet on the histological evaluation of the liver tissue is presented in Figure 1. Hepatic steatosis can be observed in the CON group with fatty infiltration around the portal space. Fish and Echium oils attenuated hepatic steatosis, whereas algae oil did not promote any protection against the hepatic steatosis induced by the high fat diet. The N-3 FA must be present in liver to exert their effects on lipid metabolism. Of the main N-3 FA applied in our study (ALA, SDA, EPA and DHA) (Figure 2), only EPA was observed in a higher concentration in the liver homogenate of animals supplemented with fish and Echium oils (Table 5). Moreover, a lower omega 6/ omega 3 ratio $(\mathrm{N}-6 / \mathrm{N}-3$ FA ratio) $(\mathrm{p}<0.001)$ was observed in liver of animals supplemented with Echium oil (Table 5). In order to better investigate the action of N-3 FA on the hepatic steatosis, two transcription factors involved in lipid metabolism were evaluated. Figures 3 and 4 present the influence of the N-3 FA supplementation on the hepatic transcription factors LXR $\alpha$ and PPAR $\alpha$, which are associated with fatty acids synthesis and oxidation, respectively. Animals supplemented with algae oil experienced a significant increase of PPAR $\alpha$ expression when compared to all other groups (Figure 3). A decrease in LXR $\alpha$ expression was observed in the groups supplemented with fish and algae oils (Figure 4), whereas Echium oil did not alter any of these two transcription factors.

\section{Discussion}

The three sources of N-3 FA fatty acids were effective in improving the plasma lipid profile of the LDLr knockout mice. Among them, Echium oil provided the best results in terms of VLDL and total cholesterol reduction and contributed to the attenuation of hepatic steatosis. None of these oils was able to reduce the inflammation caused by the high fat diet, according to the biomarkers evaluated in this study.

The supplementation with fish and Echium oils increased EPA concentrations in liver homogenate. The capacity of SDA to increase EPA content in different tissues is still controversial. Zhang et al. [20] reported that the supplementation of LDLr knockout mice with Echium oil ( $10 \%$ of total energy intake) resulted in a significant enrichment of EPA in plasma lipids. According Harris [21] the direct dietary intake of SDA has been proposed to be another strategy to increase tissue EPA levels, since SDA does not depend of $\Delta 6$-desaturase to be converted in EPA.
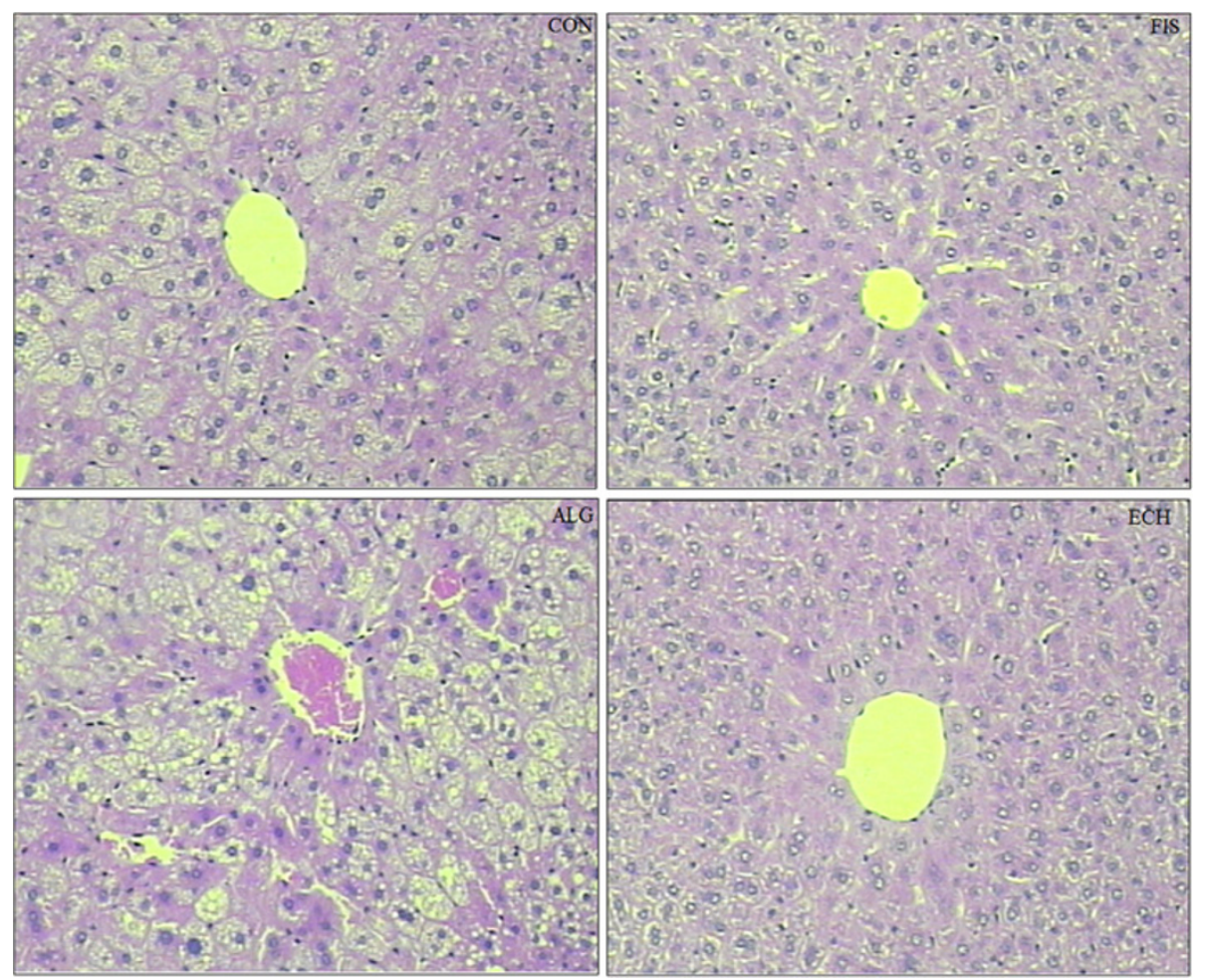

Figure 1 Representative photomicrographs of liver sections: (CON) - fatty infiltration around the portal space; (FIS) and (ECH) antisteatogenic effect exhibiting well-defined cells and low-fat vacuoles in the cytoplasm, and (ALG): hepatocytes presenting fatty infiltration around the portal space. Original magnification 10X. 


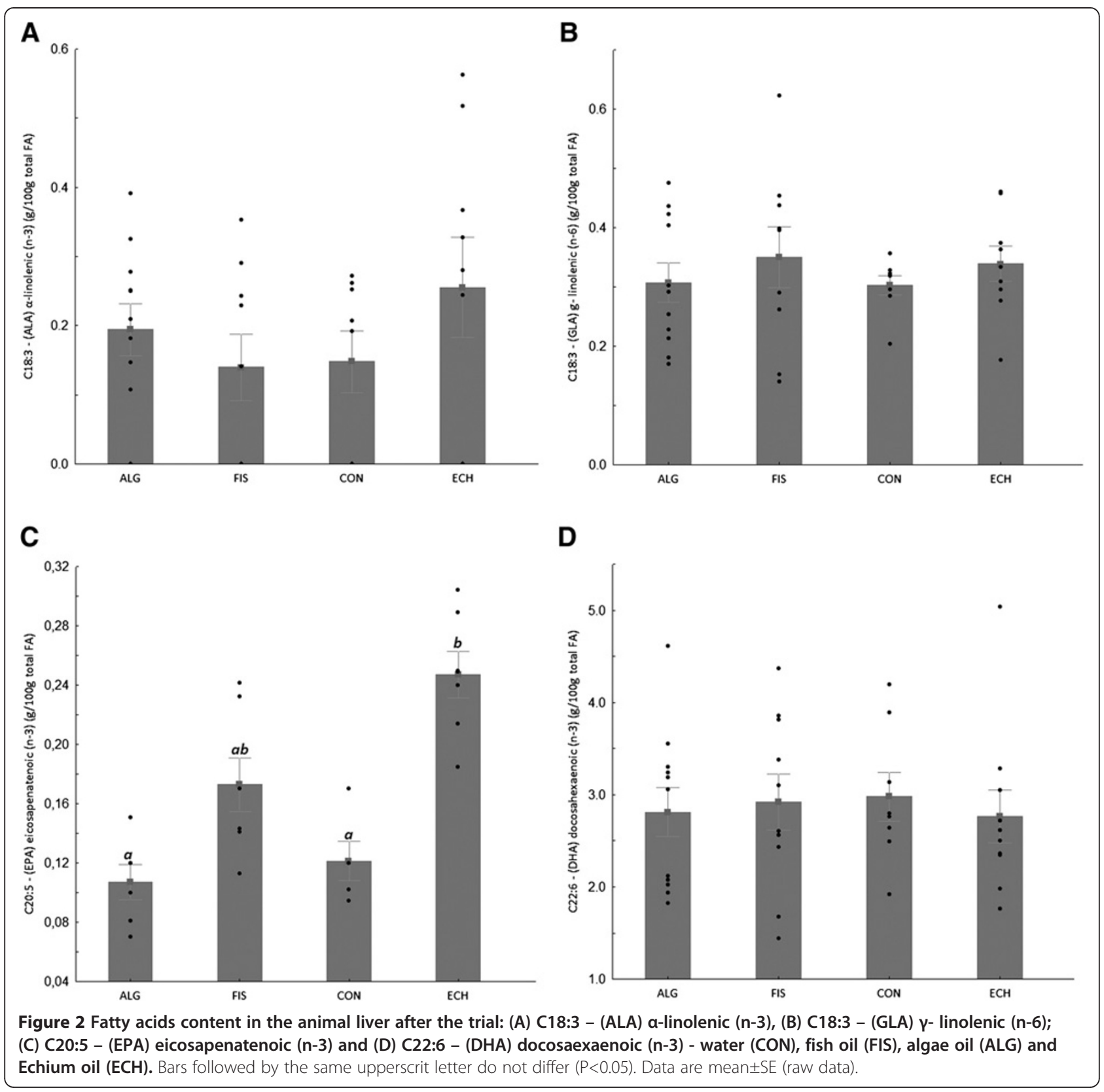

LXRs and PPARs are nuclear receptors that play crucial role in the regulation of fatty acid metabolism [22]. The hypolipidaemic effect of algae and fish oils has been partially attributed to the downregulation of LXR $\alpha$, with a subsequent inhibition of fatty acid synthesis, associated with the upregulation of PPAR $\alpha$, which promotes $\beta$-oxidation. Several studies have demonstrated that EPA and DHA reduce TG and VLDL acting as PPAR $\alpha$ agonists and LXR $\alpha$ antagonists [5,23,24]. According to Chilton et al. [3], SDA and EPA reduce the level of mRNA for Sterol Regulatory Element-Binding Protein 1C (SREBP1c), Fatty Acid Synthase (FAS) and stearoyl CoA desaturase 1 (SCD) in liver, suggesting that a possible mechanism to explain TG reduction would be associated with a decrease in the LXR $\alpha$ and consequently in the genes that codify proteins involved in fatty acids hepatic synthesis. This mechanism could be clearly observed to the both marine oils applied in our study, but not to the Echium oil. Animals supplemented with Echium oil showed the most significant VLDL reduction and attenuated steatosis, although no differences had been in regards to LXR $\alpha$ and PPAR $\alpha$ expression. In fact, the mechanisms for the reduction of the plasma TG levels by Echium oil are unknown. Although the dose applied in our study was 5 -fold lower, our results agree with those reported by Zhang et al. [20], who observed a reduction in TG and 
Table 5 Major fatty acids composition in liver homogenate (g/100 $\mathrm{g}$ Total FA) observed in the supplemented groups

\begin{tabular}{|c|c|c|c|c|c|}
\hline Fatty acids & CON & FIS & ALG & $\mathrm{ECH}$ & $P^{1}$ \\
\hline C14:0 - myristic acid & $0.47 \pm 0.08$ & $0.46 \pm 0.06$ & $0.50 \pm 0.08$ & $0.41 \pm 0.08$ & 0.079 \\
\hline C16:0 - palmitic acid & $26.37 \pm 1.96$ & $28.73 \pm 4.15$ & $27.60 \pm 3.20$ & $29.99 \pm 3.91$ & 0.163 \\
\hline C18:0 - stearic acid & $12.11 \pm 3.85$ & $13.43 \pm 4.98$ & $10.50 \pm 2.74$ & $15.61 \pm 6.43$ & 0.107 \\
\hline C18:1- oleic acid & $27.09 \pm 6.25$ & $26.4 \pm 6.33$ & $29.5 \pm 4.87$ & $22.15 \pm 7.34$ & 0.074 \\
\hline C18:2 - (LNA) linoleic $(n-6)$ & $12.87 \pm 3.22$ & $11.40 \pm 4.82$ & $12.53 \pm 5.81$ & $10.07 \pm 4.64$ & 0.584 \\
\hline C18:3 - (ALA) a-linolenic (n-3) & $0.15 \pm 0.13$ & $0.14 \pm 0.14$ & $0.19 \pm 0.12$ & $0.26 \pm 0.22$ & 0.744 \\
\hline C18:3 - (GLA) p-linolenic ( $n-6)$ & $0.30 \pm 0.05$ & $0.35 \pm 0.15$ & $0.31 \pm 0.11$ & $0.34 \pm 0.09$ & 0.396 \\
\hline C20:4- (ARA) arachidonic (n-6) & $6.69 \pm 1.85$ & $5.31 \pm 1.46$ & $4.80 \pm 1.26$ & $4.55 \pm 1.22$ & 0.060 \\
\hline C20:5 - (EPA) eicosapenatenoic ( $n-3)$ & $0.12 \pm 0.04^{\mathrm{a}}$ & $0.17 \pm 0.06^{\mathrm{ab}}$ & $0.11 \pm 0.05^{\mathrm{a}}$ & $0.25 \pm 0.04^{b}$ & 0.004 \\
\hline C22:6 -(DHA) docosahexaenoic ( $n-3)$ & $2.98 \pm 0.75$ & $2.92 \pm 0.96$ & $2.81 \pm 0.88$ & $2.76 \pm 0.92$ & 0.951 \\
\hline $\mathrm{N}-6 \mathrm{FA}$ & 19. $86 \pm 3.56^{b}$ & $17.06 \pm 5.78^{\mathrm{ab}}$ & $17.64 \pm 6.61^{\mathrm{ab}}$ & $14.97 \pm 5.81^{\mathrm{a}}$ & 0.017 \\
\hline$N-3 F A$ & $3.25 \pm 0.70$ & $3.23 \pm 0.98$ & $3.12 \pm 0.95$ & $3.27 \pm 0.96$ & 0.982 \\
\hline$N-6 / N-3 F A$ & $6.11 \pm 1.46^{\mathrm{a}}$ & $5.27 \pm 1.08^{\mathrm{a}}$ & $5.65 \pm 1.54^{a}$ & $4.58 \pm 1.41^{\mathrm{b}}$ & $<0.001$ \\
\hline
\end{tabular}

${ }^{1}$ Probability value obtained by ANOVA. Values followed by the same letter are not significantly different at the $0.05 ; a$, b: $p<0.05$ ( $n$ 6-10 animals/group).

VLDL levels after Echium oil supplementation without changes in PPAR $\alpha$ and LXR $\alpha$ expression. These results suggest that Echium oil can exert its beneficial effect on lipid metabolism and hepatic steatosis via mechanisms other than those reported for marine oils. In addition, it has been recommended [25] that studies involving SDA adopt a dose equivalent to EPA for supplementation. However, when this procedure was carried out in our study (Table 3), N-6/N-3 FA ratio of emulsion containing Echium oil (6.7) became lower than emulsions with algae
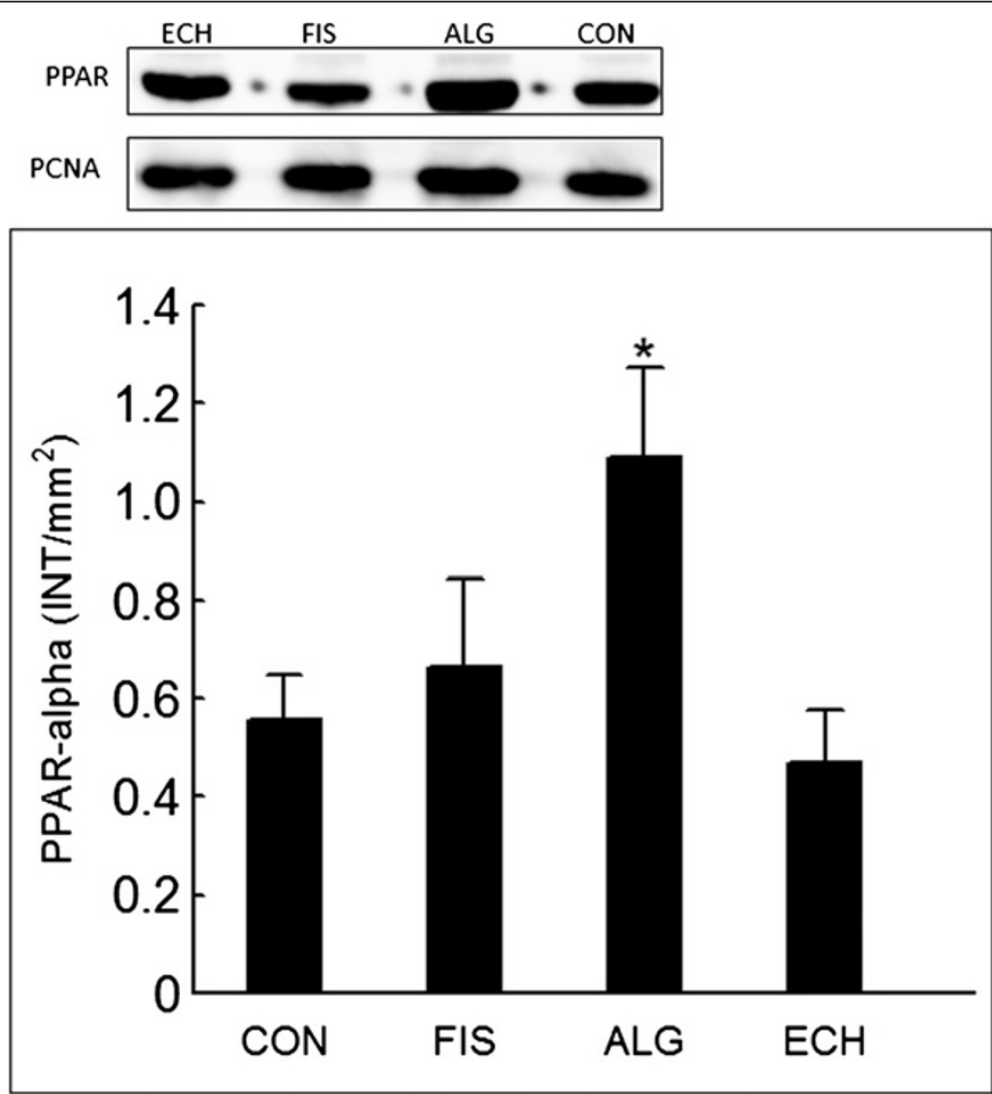

Figure 3 Changes in PPARa expression after 4 weeks of supplementation - water (CON), fish oil (FIS), algae oil (ALG) and Echium oil (ECH). ${ }^{*} \mathrm{P}<0.05$. 


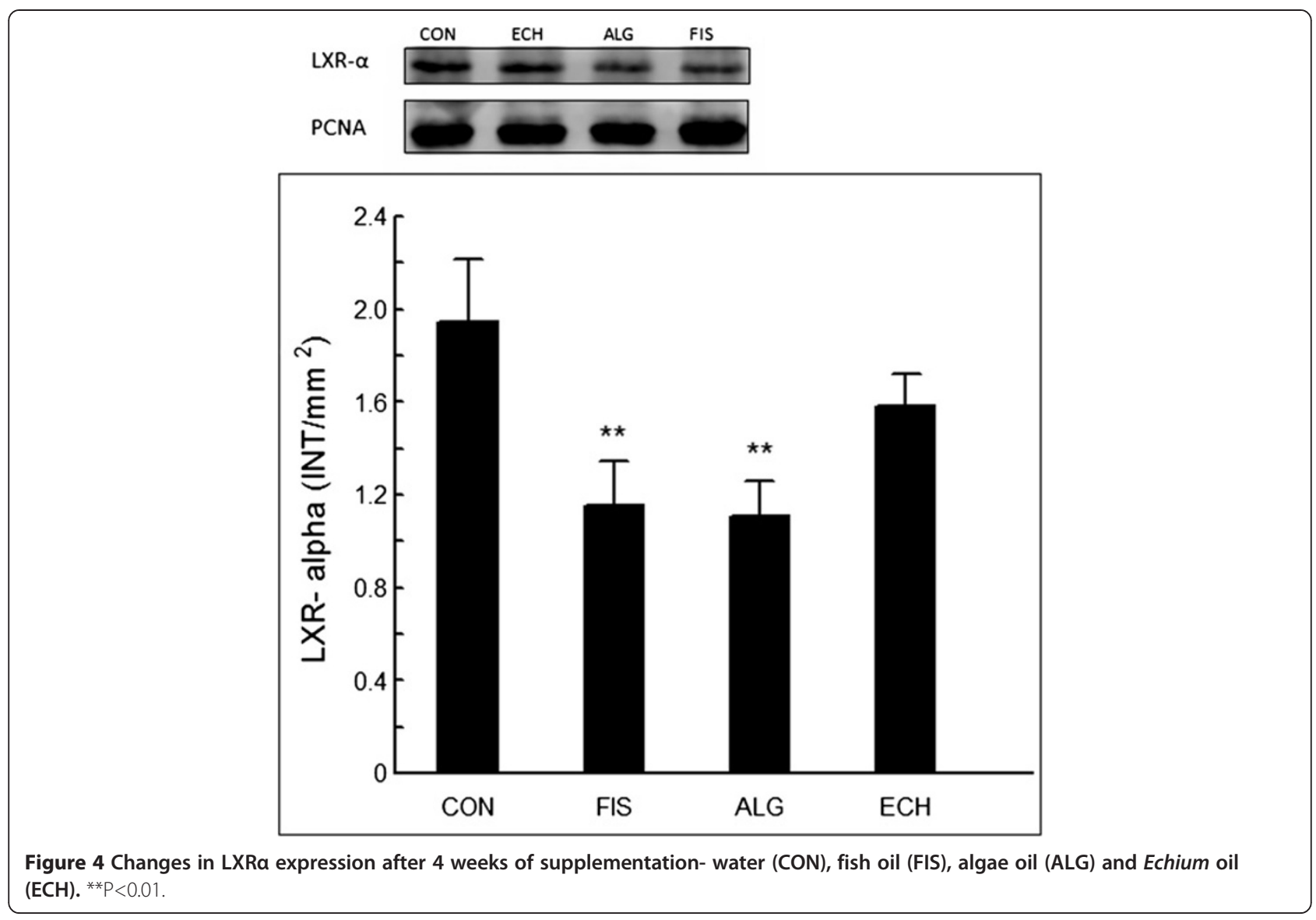

(16.7) and fish (16.6) oils. Thus, differences observed in biomarkers between ECH group and the other two supplemented groups (ALG and FIS) can have also been influenced by these difference in N-6/N-3 FA ratio.

Mice supplemented with Echium oil showed reduction of N-6/N-3 ratio in liver (Table 5). According to Parker et al. [26] the increase of N-6/N-3 FA ratio in liver is associated with higher steatosis, since this condition can favor lipogenesis and inflammation processes. These findings have also been confirmed in human and animal studies $[27,28]$. Thus, the lower N-6/N-3 FA ratio in liver homogenate can have contributed to the attenuation of steatosis observed in $\mathrm{ECH}$ group.

None of these three N-3 FA fatty acids sources was able to reduce serum inflammatory biomarkers. Ishihara et al. [29] observed that, in whole blood of Balb/c mice, the production of Tumor Necrosis Factor - $\alpha$ (TNF $\alpha)$ was suppressed by ALA, SDA and EPA supplementation. However, the dose applied by the authors was 53 -fold higher than the dose used in our study. Our high-fat diet was formulated on basis of the diet applied by Safwat et al. [30] to promote hepatic steatosis in rats. The authors observed that after 10 weeks, the animals developed hepatic steatosis, insulin resistance, hypertriglyceridaemia, and increased VLDL levels, but they observed no evidence of hepatic inflammation or fibrosis, suggesting that the hepatic steatosis was in its early stages. It is possible that the dose of EPA, DHA and SDA used in our study, although corresponding to an intake of $2 \mathrm{~g} /$ day for humans, was not sufficient to reduce the inflammation biomarkers when the process is at its initial steps. In spite of this, the high N6/N3 FA ratio present in the diet (16:1), typical of Western diet [5], may have annulled the potential LC N-3 PUFA anti-inflammatory action due to the higher availability of ARA than EPA as substrate to the oxidation mediated by cyclooxygenase and lipooxygenase enzymes.

\section{Conclusions}

In our study, the supplementation with three different sources of N-3 FA fatty acids was evaluated using LDLr knockout animals fed with a high fat diet. It was observed that the best combination of results, in terms of plasma lipid profile and steatosis, was achieved by the supplementation with Echium oil, and the mechanism involved in this favourable result seems to be different from those involved with EPA and DHA metabolism, maybe due to the lower N-6/N-3 FA ratio present in the 
liver of animals supplemented with Echium oil. Theoretically, it is possible to transfer a metabolic pathway for EPA and DHA synthesis from a marine organism to an oilseed crop plant [14]. However, while this option is not available, our study confirms that Echium oil represents an alternative as natural ingredient to be applied in functional foods to reduce cardiovascular disease risk.

\begin{abstract}
Abbreviations
ALA: a - Linolenic acid; ALG: Algae oil group; CON: Control group; CRP: Creactive protein; CVD: Cardiovascular disease; DHA: Docosahexaenoic acid; ECH: Echium oil group; EPA: Eicosapentaenoic acid; FAME: Fatty acid methyl ester; FDA: Food and drug administration; FIS: Fish oil group; HDL: High density lipoprotein; ICAM: Inter-cellular adhesion molecule; IL- 6: Interleukin 6; LDL: Low density lipoprotein; LDL: Receptor deficient mice; LDL: Knockout mice; LNA: Linoleic acid; LXR- a: Liver X receptor a; LC n-3 PUFA: Long-chain n-3 polyunsaturated fatty acids; N-3 FA: Omega 3 fatty acids; N-6/N-3 FA: Omega 6 fatty acids/omega 3 fatty acids; PPAR-a: Peroxisome proliferator activated receptor a; SDA: Stearidonic acid; TG: Triacylglycerol; TNF- a: Tumor necrosis factor - $a_{\text {; }}$ VCAM: Vascular cell adhesion molecule; VLDL: Very low density lipoprotein.
\end{abstract}

\section{Competing interest}

The authors have no conflict of interest to declare.

\section{Authors' contributions}

PBB conducted the research and wrote the manuscript. KRM performed part of the experiments. MMR participated in critical revision of the study. IAC contributed to the design of the study, analysis of data, drafting the manuscript and was responsible for the financial support. IAC had primary responsibility for the final content. All the authors read and approved the final manuscript

\section{Acknowledgements}

The authors thank to FAPESP (09/15649-7; 10/12042-1, 10/08225-3) for the financial support.

\section{Author details}

'LADAF. NAPAN. Department of Food and Experimental Nutrition, Faculty of Pharmaceutical Sciences, University of São Paulo, Av. Lineu Prestes, 580, São Paulo B14 - 05508-900, Brazil. ²Department of Nutrition, Faculty of Public Health, University of São Paulo, São Paulo, Brazil.

Received: 20 December 2012 Accepted: 1 March 2013

Published: 19 March 2013

\section{References}

1. Blasbalg TL, Hibbeln JR, Ramsden CE, Majchrzak SF, Rawlings RR: Changes in consumption of omega-3 and omega- 6 fatty acids in the United States during the 20th century. Am J Clin Nutr 2011, 93:950-62.

2. Shapiro H, Tehilla M, Attal-Singer J, Bruck R, Luzzatti R, Singer P: The therapeutic potential of long-chain omega-3 fatty acids in nonalcoholic fatty liver disease. Clin Nutr 2011, 30:6-19.

3. Chilton FH, Rudel LL, Parks JS, Arm JP, Seeds MC: Mechanisms by which botanical lipids affect inflammatory disorders. Am J Clin Nutr 2008, 87:498S-503S

4. Balk EM, Lichtenstein AH, Chung M, Kupelnick B, Chew P, Lau J: Effects of omega-3 fatty acids on serum markers of cardiovascular disease risk: a systematic review. Atherosclerosis 2006, 189:19-30.

5. Adkins Y, Kelley DS: Mechanisms underlying the cardioprotective effects of omega-3 polyunsaturated fatty acids. J Nutr Biochem 2010, 21:781-92.

6. Food and Drug Administration: Office of nutritional products, labeling, and dietary supplements, center for food safety and applied nutrition, US food and drug administration. Omega-3 fatty acids \& coronary heart disease. Docket No. 2003Q-0401. http://www.fda.gov/Food/GuidanceRegulation/ GuidanceDocumentsRegulatoryInformation/LabelingNutrition/ucm064923. htm. Accessed February 27, 2013.

7. Kris-Etherton PM, Harris WS, Appel L: Fish comsumption, fish oil, omega-3 fatty acids, and cardiovascular disease. Circulation 2002, 106:2747-57.
8. Wang C, Harris WS, Chung M, Lichtenstein AH, Balk EM, Kupelnick B, Jordan HS, Lau J: n-3 Fatty acids from fish or fish-oil supplements, but not alinolenic acid, benefit cardiovascular disease outcomes in primary- and secondary-prevention studies: a systematic review. Am J Clin Nutr 2006, 84:5-17.

9. Barceló-Coblijn G, Murphy EJ: Alpha-linolenic acid and its conversion to longer chain $\mathrm{n}-3$ fatty acids: benefits for human health and a role in maintaining tissue n-3 fatty acid levels. Prog Lipid Res 2009, 48:355-74.

10. Lemke SL, Vicini JL, Su H, Goldstein DA, Nemeth MA, Krul ES, Harris WS: Dietary intake of stearidonic acid-enriched soybean oil increases the omega-3 index: randomized, double-blind clinical study of efficacy and safety. Am J Clin Nutr 2010, 92:766-75.

11. Venegas-Calerón M, Sayanova O, Napier JA: An alternative to fish oils: metabolic engineering of oil-seed crops to produce omega-3 long chain polyunsaturated fatty acids. Prog Lipid Res 2010, 49:108-19.

12. Poudyal H, Panchal SK, Diwan V, Brown L: Omega-3 fatty acids and metabolic syndrome: effects and emerging mechanisms of action. Prog Lipid Res 2011, 50:372-87.

13. Tahvonen RL, Schwab US, Linderborg KM, Mykkänen HM, Kallio HP: Black currant seed oil and fish oil supplements differ in their effects on fatty acid profiles of plasma lipids, and concentrations of serum total and lipoprotein lipids, plasma glucose and insulin. J Nutr Biochem 2005, 16:353-9.

14. Damude HG, Kinney AJ: Engineering oilseed plants for a sustainable, land-based source of long chain polyunsaturated fatty acids. Lipids 2007, 42:179-85.

15. Yamazaki K, Fujikawa M, Hamazaki T, Yano S, Shono T: Comparison of the conversion rates of alpha-linolenic acid (18:3(n-3)) and stearidonic acid $(18: 4(\mathrm{n}-3))$ to longer polyunsaturated fatty acids in rats. Biochim Biophys Acta 1992, 1123:18-26.

16. Whelan J: Dietary stearidonic acid is a long chain $(n-3)$ polyunsaturated fatty acid with potential health benefits. J Nutr 2009, 139:5-10.

17. AOAC: Official methods n. 996.06, Fat (Total, Saturated, and Monounsaturated) in Foods. Offic Meth Anal 2002, 41:20-24A.

18. Friedewald WT, Levy Rl, Fredrickson DS: Estimation of the concentration of low-density lipoprotein cholesterol in plasma without use of the preparative ultracentrifuge. Clin Chem 1972, 18:499-502.

19. Tillmann T, Kamino K, Dasenbrock C, Kohler M, Morawietz G, Campo E, Cardesa A, Tomatis L, Mohr U: Quality control of three methods for lung tumorigenesis studies. Exp Toxicol Pathol 1999, 51:99-104.

20. Zhang P, Boudyguina E, Wilsom MD, Gebre AK, Parks JS: Echium oil reduces plasma lipids and hepatic lipogenic gene expression in apoB100-only LDL receptor knockout mice. J Nutr Biochem 2008, 19:655-63.

21. Harris WS: Stearidonic acid-enhaced soybean oil: a plant-based source of n-3 fatty acids for foods. J Nutr 2012, 142:600S-604S.

22. Yoshikawa T, Ide T, Shimano H, Yahagi N, Amemiya-Kudo M, Matsuzaka T, Yatoh S, Kitamine T, Okazaki H, Tamura Y, Sekiya M, Takahashi A, Hasty AH, Sato R, Sone H, Osuga J, Ishibashi S, Yamada N: Cross-talk between peroxisome proliferator-activated receptor (PPAR) alpha and liver X receptor (LXR) in nutritional regulation of fatty acid metabolism. I. PPARs suppress sterol regulatory element binding protein-1c promoter through inhibition of LXR signaling. Mol Endocrinol 2003, 17:1240-54.

23. Byrne CD: Fatty liver: role of inflammation and fatty acid nutrition. Prostaglandins Leukot Essent Fatty Acids 2010, 82:265-71.

24. Harris WS, Miller M, Tighe AP, Davidson MH, Schaefer EJ: Omega-3 fatty acids and coronary heart disease risk: clinical and mechanistic perspectives. Atherosclerosis 2008, 197:12-24.

25. Whelan J, Gouffon J, Zhao Y: Effects of dietary stearidonic acid on biomarkers of lipid metabolism. J Nutr 2012, 142:630S-634S.

26. Parker HM, Johnson NA, Burdon CA, Cohn JS, O' Connor HT, George J: Omega-3 supplementation and non-alcoholic fatty liver disease: a systematic review and meta-analysis. J Hepatol 2012, 56:944-951.

27. Sekiya M, Yahagi N, Matsuzaka T, Najima Y, Nakakuki M, Nagai R, Ishibashi S, Osuga J, Yamada N, Shimano H: Polyunsaturated fatty acids ameliorate hepatic steatosis in obese mice by SREBP-1 suppression. Hepatology 2003, 38:1529-1539.

28. Araya J, Rodrigo $R$, Videla $L A$, Thielemann $L$, Orellana $M$, Pettinelli $P$, Poniachik J: Increase in long-chain polyunsaturated fatty acid n-6/n-3 ratio in relation to hepatic steatosis in patients with non-alcoholic fatty liver disease. Clin Sci 2004, 106:635-643. 
29. Ishihara K, Komatsu W, Saito H, Shinohara K: Comparison of the effects of dietary a- Linolenic, stearidonic, and eicosapentaenoic acids on production of inflammatory mediators in mice. Lipids 2002, 37:481-6.

30. Safwat GM, Pisanò S, D'Amore E, Borioni G, Napolitano M, Kamal AA, Ballanti P, Botham KM, Bravo E: Induction of non-alcoholic fatty liver disease and insulin resistance by feeding a high-fat diet in rats: does coenzyme $\mathrm{Q}$ monomethyl ether have a modulatory effect? Nutrition 2009, 25:1157-68.

doi:10.1186/1476-511X-12-38

Cite this article as: Botelho et al: Effect of Echium oil compared with marine oils on lipid profile and inhibition of hepatic steatosis in LDL knockout mice. Lipids in Health and Disease 2013 12:38.

\section{Submit your next manuscript to BioMed Central and take full advantage of:}

- Convenient online submission

- Thorough peer review

- No space constraints or color figure charges

- Immediate publication on acceptance

- Inclusion in PubMed, CAS, Scopus and Google Scholar

- Research which is freely available for redistribution 